\title{
PELOS FIOS LITERÁRIOS: \\ UMA PROPOSTA DE ENSINO ALIANDO APRENDIZAGEM BASEADA EM PROJETOS, TECNOLOGIA E LITERATURA
}

\section{THROUGH LITERARY YARNS: \\ A TEACHING PROPOSAL ALLYING PROJECT BASED LEARNING, TECHNOLOGY AND LITERATURE}

\begin{abstract}
Ana Cecília Leal Machado ${ }^{1}$
Resumo: Este relato de experiência apresenta um conjunto de atividades realizadas com turmas do $7^{\circ}$ ano a partir de uma obra literária contemporânea. Sua metodologia contempla o Google Classroom, com os alunos trabalhando em grupo a partir do livro e de temas de próprio interesse relacionados à narrativa, culminando na criação de vídeos. As atividades se fundamentaram na Aprendizagem Baseada em Projetos, no potencial humanizador da literatura e no letramento literário, almejando desenvolver competências da Base Nacional Comum Curricular.

Palavras-chave: literatura; aprendizagem baseada em projetos; tecnologia.

Abstract: This experience report presents a set of activities performed with $7^{\text {th }}$ grade students whose starting point was a contemporary literary work. The methodology includes Google Classroom, with students working in groups taking into account not only the book but also topics of their own interest related to the narrative, culminating in the creation of videos. The activities were based on Project Based Learning, on the humanizing potential of literature and on literary literacy, aiming to develop competences of the Common National Curricular Base.
\end{abstract}

Keywords: literature; project based learning; technology.

\section{Introdução}

Ao se pensar a presença da Literatura em sala de aula, reconhece-se a dificuldade de trabalhar o texto literário nas escolas. É consenso a necessidade de transformar a educação e dar a ela um caráter diferenciado, sintonizado com as exigências do século XXI, mas, quando se trata da leitura, os desafios parecem ainda maiores. Não restam dúvidas de que ler é passo essencial na formação de cidadãos efetivamente críticos e engajados, porém, a dilatação do mundo tecnológico se apresenta como um desafio aos professores, em especial aos de língua.

Os alunos dos Anos Iniciais do Ensino Fundamental parecem ter ainda o prazer de ler, substituído, no Ensino Médio, pela obrigação das leituras para os vestibulares, em especial nos estados em que há listas de obras obrigatórias para provas. Entre essas duas etapas, porém, os

\footnotetext{
1 Mestranda em Linguística Aplicada pela Universidade de Taubaté (UNITAU). E-mail: ana.lealmachado@gmail.com
} 
pequenos leitores vão, aos poucos, afastando-se dos livros, começam a considerar ler um ato enfadonho, buscam novas formas de prazer. Os Anos Finais do Ensino Fundamental, portanto, parecem ser o segmento em que a leitura como fruição estética, como gosto, perde força. A maioria das escolas não tem aulas específicas de Literatura para esse segmento e, durante as atividades de leitura, pouco se faz para apreciar o viés estético do texto ou mesmo para se estimular o gosto por tal hábito. Quando chegam ao Ensino Médio, evidentemente, muitos estudantes não verão as grandes obras da literatura mundial e suas análises como atrativas, e sim como mais um ponto a cumprir entre os conteúdos obrigatórios. Por consequência, na maioria das vezes, serão adultos que não procuram livros.

Mudar esse cenário não é tarefa fácil. Na verdade, muitos professores sequer sabem por onde começar a resolver tal questão. Não é incomum ouvir professores dizendo que "os jovens já não querem ler”, mas será que a escola busca seduzir os leitores? Mais do que isso, será que cabe apenas ao professor de língua portuguesa o trabalho com os livros?

Este relato de experiência tem como objetivo apresentar um conjunto de atividades aplicadas, ao longo do ano de 2018, em turmas do $7^{\circ}$ ano do Ensino Fundamental a partir de uma obra literária. O livro escolhido foi Diálogos de Samira: por dentro da guerra síria (CAMARGO, M. CARUSO, C., 2015), que, como denunciado pelo título, traz um tema atual, presente nos noticiários e, por isso, familiar aos estudantes.

Ciente de que as tecnologias são parte do cotidiano dos alunos e precisam ser inseridas em sala de aula, os procedimentos metodológicos contemplam tecnologias de informação e comunicação, em particular o Google Classroom, ferramenta do conjunto Google for Education. Além disso, o trabalho baseou-se na teoria da Aprendizagem Baseada em Projetos (BENDER, 2014) e se preocupou em desenvolver as competências previstas na Base Nacional Comum Curricular (2018), nova diretriz do ensino brasileiro.

Partindo das considerações de Antonio Candido (1995) sobre o potencial humanizador da Literatura e da proposta de Nelly Novaes Coelho (2000) de utilizar a Literatura como eixo organizador do ensino, o trabalho encontra eco também nas ideias de Rojo (2004) sobre letramento para organizar as atividades aqui descritas. Já colocando em foco ideias relacionadas à Literatura e ao letramento literário, fazem-se presentes reflexões de Cosson (2016) e Colomer (2007). Descrevendo os passos que compuseram o projeto, este relato pretende subsidiar a prática docente pela apresentação de uma forma diferenciada de trabalhar o livro em sala de aula. Espera-se tornar evidente que, com um ambiente de aprendizagem centrado no aluno e 
com o professor aliando-se às tecnologias para exercer o papel de orientador, constrói-se um ensino significativo e a Literatura torna-se, como sempre deve ser, um prazer.

Começando pela retomada de algumas ideias chave sobre leitura, letramento e literatura e passando pelos fundamentos da aprendizagem baseada em projetos, o relato apresentará os procedimentos adotados ao longo de toda as atividades aqui descritas. Ao final, será analisado o encaminhamento do projeto e avaliado seu valor como ferramenta a ser utilizada por outros docentes.

\section{Leitura, letramento e literatura}

Hoje, já na segunda década do século XXI, a educação precisa se transformar, pois o que funcionava há quarenta anos, ou até menos, há vinte, já não satisfaz as crianças e os jovens contemporâneos, imersos na tecnologia desde o nascimento. Nesse cenário, o desenvolvimento da leitura e o prazer da literatura tem se perdido, em um caminho, na opinião de muitos professores, irreversível. Segundo Cosson (2016, p. 20), "para muitos professores e estudiosos da área de Letras, a literatura só se mantém na escola por força da tradição e inércia curricular, uma vez que a educação literária é um produto do século XIX que já não tem razão de ser no século XXI". Porém, há muito que pode ser feito para que os alunos leiam e tenham prazer em ler, ressignificando a literatura em sala de aula, afinal, “a contribuição da literatura na construção social do indivíduo e da coletividade não é apenas essencial, mas simplesmente inevitável” (COLOMER, 2007, p. 20). O processo pode não ser fácil, mas é, com certeza, possível.

Não restam dúvidas sobre a importância da escola no desenvolvimento da leitura das crianças e dos jovens. Porém, ler, no ambiente escolar, tem sido cada vez menos visto como um ato prazeroso e cada vez mais associado à identificação de características de gêneros e de informações. Roxane Rojo evidencia que "a escolarização, no caso da sociedade brasileira, não leva à formação de leitores e produtores de texto proficientes e eficazes e, às vezes, chega mesmo a impedi-la" (ROJO, 2004, p. 1). Para a autora, o ato de ler é complexo e preenchido por variáveis, distanciando-se da abordagem muitas vezes simplista e superficial com que se desenvolve nas escolas, em que se tem ensinado, avaliado e cobrado somente poucas e as mais básicas capacidades leitoras. Muito além de aspectos estruturais do texto, é importante pensar em ler como ato que "implica troca de sentidos não só entre escritor e leitor, mas também com 
a sociedade onde ambos estão localizados, pois os sentidos são resultado de compartilhamentos de visões do mundo entre os homens no tempo e no espaço" (COSSON, 2016, p. 27).

Somente quando a escola encara o desenvolvimento da leitura como um ato de prazer, de autonomia do leitor, de formação crítica do cidadão, e não como uma atividade de decodificação, o ato de ler é reconhecido como importante prática social para a consolidação de uma sociedade efetivamente letrada. Sendo a leitura "um ato de cognição, de compreensão, que envolve conhecimento de mundo, conhecimento de práticas sociais e conhecimentos linguísticos muito além dos fonemas" (ROJO, 2004, p. 3), o trabalho com o texto é, antes de tudo, uma atividade que busca o letramento dos alunos.

Diante disso, a escola deve ser vista como "um universo onde convivem letramentos múltiplos e diferenciados, cotidianos e institucionais, valorizados e não-valorizados, locais, globais e universais, vernaculares e autônomos, sempre em contato e em conflito" (ROJO, 2009, p. 106-107). Essa instituição deve ter por objetivo permitir que seus alunos participem de diversas práticas sociais que envolvam leitura e escrita, sempre de forma ética, democrática e crítica. Tais pretensões dialogam diretamente com a nova Base Nacional Comum Curricular (2018), doravante BNCC, documento normativo do Ministério da Educação que regula as aprendizagens essenciais da educação básica brasileira. Ao tratar da Língua Portuguesa como disciplina escolar, explicita que cabe à escola "proporcionar aos estudantes experiências que contribuam para a ampliação dos letramentos, de forma a possibilitar a participação significativa e crítica nas diversas práticas sociais permeadas/constituídas pela oralidade, pela escrita e por outras linguagens" (BRASIL, 2018, p. 65-66).

Nesse contexto, a literatura é importante instrumento para o trabalho em sala de aula. Antonio Candido (1995) já nos alertava de que a literatura é uma arte de extremo valor e que se relaciona a todas as outras esferas da atividade humana. $\mathrm{Na}$ arte literária, é essencial a integração entre forma e conteúdo, mas ela não pode ser pensada apenas por esse viés. Por ser uma fonte de emoção e de conhecimento, ela permite reflexões, significados e visões de mundo, ajudando-nos na ordenação da mente, dos sentimentos. Torna-se, assim, um instrumento no processo de humanização "na medida em que nos torna mais compreensivos e abertos para a natureza, a sociedade, o semelhante" (CANDIDO, 1995, p. 249), encontrando eco no proposto por Colomer (2007, p. 27):

o texto literário ostenta a capacidade de reconfigurar a atividade humana e oferece instrumentos para compreendê-la, posto que, ao verbalizá-la, cria um espaço específico no qual se constroem e negociam os valores e o sistema estético de uma cultura. Essa ideia básica contribui para a nova argumentação sobre a importância da literatura no processo educativo. 
Deve-se chamar a atenção, como já feito por Candido (1995), para o fato de que a literatura nos ajuda a conhecer a sociedade, retomando a ideia de literatura social, uma literatura empenhada, que engloba níveis intencionais de conhecimento por parte do autor e assimilados de forma consciente pelos leitores. Nessa perspectiva, não só as obras mais grandiosas e com maior prestígio como também as produções literárias de qualidade mais modesta são importantes, afinal, "é preciso entender a literatura para além de um conjunto de obras valorizadas como capital cultural de um país” (COSSON, 2016, p. 34).

Tal reconhecimento faz parte também das propostas da BNCC, que explicita

a potência da arte e da literatura como expedientes que permitem o contato com diversificados valores, comportamentos, crenças, desejos e conflitos, o que contribui para reconhecer e compreender modos distintos de ser e estar no mundo e, pelo reconhecimento do que é diverso, compreender a si mesmo e desenvolver uma atitude de respeito e valorização do que é diferente. (BRASIL, 2018, p. 137)

É inegável, portanto, que o trabalho com obras literárias na escola é fundamental para a formação de "um sujeito leitor livre, responsável e crítico - capaz de construir o sentido de modo autônomo e de argumentar sua recepção (...), a formação de uma personalidade sensível e inteligente, aberta aos outros e ao mundo que esse ensino da literatura vislumbra. (ROUXEL, 2013, p. 20). Porém, com as tecnologias invadindo a sala de aula em uma velocidade nunca antes vista, o desafio do ensino de literatura é gigante, exigindo da escola e do professor a reformulação das posturas adotadas no processo de ensino e aprendizagem. É para essa necessidade que Ivanda Martins (2006) chama a atenção, destacando o quão difícil é fornecer subsídios teóricos e metodológicos para a prática dos professores. Fundamentar essa prática é essencial, uma vez que, hoje, a competição de outros meios com a leitura é voraz, atendendo à necessidade de ficcionalização natural do ser humano.

Diante disso, o primeiro ponto a ser levado em consideração é que o docente não deve impor uma interpretação única da leitura; pelo contrário, ele precisa interagir com seus alunos, apresentando-lhes a diversidade de leituras de um texto literário, levando o estudante a perceber que "o sentido não está no texto, mas é construído pelos leitores na interação com textos" (MARTINS, 2006, p. 85). Isso quer dizer que o professor, conhecendo a turma e seus interesses, tendo bagagem de leitura e vontade de fazer diferente, deve mediar o processo de leitura. $\mathrm{O}$ docente que supervaloriza o cânone literário, sem dar à turma a possibilidade de se posicionar e de avaliar o texto, distancia, portanto, seu aluno. Se é a diversidade de obras com as quais o aluno tem contato que influencia seu conhecimento e sua percepção de mundo, escolher livros 
com temas de interesse dos estudantes e próximos ao que eles percebem no cotidiano pode ser um bom ponto de partida para uma atuação diferenciada. Deve-se reconhecer

a literatura como um processo de comunicação, uma leitura que demanda respostas do leitor, que o convida a penetrar na obra de diferentes maneiras, a explorá-la sob os mais variados aspectos. É só quando esse intenso processo de interação se efetiva que se pode verdadeiramente falar em leitura literária (COSSON, 2016, p. 29).

Um livro tem, muito mais do que apenas uma história sendo contada, a apresentação de contextos históricos, culturais e sociais que enriquecem a percepção do leitor sobre o mundo, dialogando com diversas áreas do conhecimento. Na escola, portanto, a obra literária não deve e nem pode ficar restrita às aulas de Português: ela pode funcionar como um eixo organizador do ensino das mais variadas disciplinas, o que Nelly Novaes Coelho (2000) já propôs como estratégia de trabalho. $\mathrm{O}$ ensino não pode se ater somente à seleção de disciplinas que se interrelacionam, ele precisa se desenvolver em torno de um tema, ligando todas as disciplinas. Nesse ensino em mutação, mais do que em crise, deixa-se o paradigma clássico, mecanicista, e caminha-se para um emergente, complexo. Não é mais o saber cumulativo, estático, que se fortalece, e sim um sistema aberto, dinâmico, que "atravesse e mostre as diferentes áreas da vida, da cultura e do conhecimento" (COELHO, p. 19, 2000): o foco está nas relações, e não no objeto em si.

Mas, se "o velho já não serve e o novo ainda não está claramente descoberto, definido e explicado" (COELHO, p. 22, 2000), exige-se dos educadores postura ativa na reflexão sobre o cenário atual e seus desdobramentos. A escola precisa reconhecer o papel de destaque que as tecnologias digitais têm hoje e terão ainda mais no futuro. Os ambientes digitais são interativos e pouco controlados, abrindo espaço para novas formas de sociabilidade a serem usadas de forma crítica. O aluno precisa se reconhecer como protagonista, sobretudo ético, para se apropriar dos textos que o circundam, que existem não só na escola, mas fora dela, para valorizar a multiculturalidade.

Hoje, em que crianças e jovens conectam-se cada vez mais a imagens, seja pelas redes sociais ou pela televisão, é fundamental que a escola reconheça a importância cultural do visual "para justificar sua introdução de forma sistemática na educação, o que implica planejamento das práticas pedagógicas, capacitação de professores e infraestrutura tecnológica" (COSTA, 2009, p. 96). Ensinar a ler e pensar imagens é, antes de tudo, capacitar os alunos a inserirem-se na sociedade do espetáculo de forma crítica, ativa e até mesmo emotiva, e não como meros assimiladores de informações. Afinal, "funções, como a de entreter e de informar, que estiveram 
principalmente a cargo da literatura em outras épocas, foram assumidas pelos meios de comunicação de massas e pelas novas tecnologias" (COLOMER, 2007, p. 22).

Agora, é o momento de os professores organizarem seus planos de ensino considerando a importância dos letramentos na escola e na vida. Obviamente, será preciso escolher o que será trabalhado de acordo com as necessidades específicas. Diante disso, todo professor que busca a formação crítica de seus alunos precisa se lembrar de que "escolhas nunca são neutras, nem impunes, pois o tempo escolar que tomo com um objeto de ensino não será dedicado a outro (...) nada em educação nunca é neutro e nossa tarefa é justamente a de fazer escolhas e encaminhamentos conscientes" (ROJO, 2009, p.121).

\section{Aprendizagem baseada em projetos}

A Aprendizagem Baseada em Projetos, doravante ABP, é uma proposta que, embora venha ganhando espaço nos últimos anos, não é completamente nova, encontrando-se registros dela desde o começo do século XX. Hoje, obviamente, suas aplicações já se configuram de forma distinta e, neste trabalho, utiliza-se a concepção de William Bender (2014) sobre a ABP.

Bender (2014) alerta que a ABP, "em um mundo onde o conhecimento se torna obsoleto no momento em que é impresso" (BENDER, 2014, p. 13), pode oferecer aos professores uma forma diferenciada e altamente produtiva de estimular os alunos a desenvolverem o gosto pelo estudo e pela aprendizagem. Nas palavras do autor, ela é "um modelo de ensino que consiste em permitir que os alunos confrontem as questões e os problemas do mundo real que consideram significativos, determinando como abordá-los e, então, agindo cooperativamente em busca de soluções" (BENDER, 2014, p. 9).

$\mathrm{Na} \mathrm{ABP}$, a investigação dos alunos é um dos pontos principais, já que, em geral, os estudantes têm algum poder de escolha sobre o que irão estudar. Tal poder, obviamente, gera mais envolvimento e participação dos alunos nos projetos, pois eles se sentem parte integrante do que desenvolvem na escola. Logo,

\footnotetext{
a $\mathrm{ABP}$ envolve muito mais do que simplesmente a tarefa de um projeto individual em uma dada unidade de ensino (...), envolve uma mudança para a aprendizagem centrada no aluno, baseada em questões e problemas autênticos e envolventes, além do uso crescente das ferramentas web 2.0 e de outras tecnologias de ensino no processo de ensino-aprendizagem.” (BENDER, 2014, p. 29)
}

Dentro da ABP, as propostas de trabalho devem surgir a partir de uma âncora, ou seja, de um ponto de partida que desenvolva a curiosidade e a vontade dos alunos de se envolverem em um processo de pesquisa e de aprendizagem. No caso do projeto aqui descrito, o livro Diálogos de Samira, que trata da guerra na Síria, funcionou como âncora, levando os estudantes 
a refletirem sobre temas até então distantes deles e pouco conhecidos. Retoma-se, assim, a ideia defendida por Coelho (2000) de que a Literatura, como ciência do imaginário, permite múltiplas reflexões, englobando diversas ciências, ajudando a organizar conhecimentos em torno de eixos de ideias, em um processo significativo de aprendizagem para o sujeito. Por isso, ela é uma disciplina adequada para "servir de eixo ou 'tema transversal' para a interligação de diferentes unidades de ensino" (COELHO, p. 24, 2000).

Tendo a âncora definida, o passo seguinte é estruturar o início do projeto em torno de uma questão motriz, "uma questão orientadora e altamente motivadora com a qual os alunos irão se identificar" (BENDER, 2015, p. 23). No caso do projeto, decidiu-se adotar mais de uma questão motriz, considerando que o livro era rico em temas e gerou diversas curiosidades nos alunos, ou seja, houve mais de um ponto motivador de pesquisas. Ao final dessas primeiras etapas, a união da âncora com a questão motriz permite aos alunos saberem que informações reunir e em que profundidade para desenvolverem o estudo do ponto escolhido. Os estudantes, podem, então, partir para as etapas práticas em busca de um produto final para o projeto, como um texto, uma apresentação de slides, um produto, uma instalação, entre várias outras possibilidades. No desenvolvimento deste projeto, optou-se pela criação de um vídeo.

Durante todo o processo de ABP, é essencial que o aluno tenha voz e poder de escolha, participando ativamente e se apropriando do projeto, reconhecendo-se como seu componente mais importante. Porém, Bender (2014) alerta que como e quando os alunos terão tal autonomia é uma decisão que cabe ao professor, adequando o processo à realidade de sua escola e de suas turmas. No caso do projeto aqui descrito, com alunos do $7^{\circ}$ ano, a cada fase das atividades deuse um pouco mais de autonomia, de certa forma, direcionada, pois ainda são estudantes novos, que precisam de orientação mais próxima.

Outro ponto essencial para o desenvolvimento da ABP é que os alunos sejam organizados em grupos, escolhidos por eles ou pelo professor. Isso porque os estudantes ganham a oportunidade de ficarem "acostumados a planejar atividades em conjunto, a especificar papéis para vários membros do grupo, a trabalhar em grupo para resolver problemas, a apoiar as ideias uns dos outros e a oferecer, mutuamente, avaliações de colegas apropriadas e úteis" (BENDER, 2014, p. 49). Costuma-se sugerir grupos de 7 a 12 alunos, mas, no projeto aqui descrito, os grupos foram consideravelmente menores, de 4 ou 5 alunos, visto que, por serem do $7^{\circ}$ ano do Ensino Fundamental, ainda têm dificuldades na divisão de funções e precisam de acompanhamento mais próximo e constante. É preciso que o professor estabeleça o cumprimento de metas específicas, utilizando prazos curtos, médios e longos, sistematizando 
e deixando clara a evolução do trabalho ao longo do tempo, já que a ABP se desenvolve por mais tempo que as atividades costumeiras das escolas. Mesmo em grupo, algumas tarefas podem ser individuais e os alunos podem até se dividir em funções: é preciso levar em conta a realidade das turmas e dos alunos para determinar a abordagem a ser seguida. É também boa ideia encorajar o planejamento escrito dos passos do projeto, evitando que os estudantes se percam em meio a muitas tarefas e ideias.

Isso leva a outro ponto importante da ABP: a realização de feedbacks e revisões. Se o trabalho deve ser realizado em etapas, com prazos marcados, o professor, atuando como orientador, deve acompanhar todo o processo e avaliar constantemente o que é feito, apontando ajustes e reformulações que possam ser necessárias. Caso isso não seja feito, o grupo pode se perder pelo caminho e não conseguir chegar ao produto final desejado de forma positiva.

Quanto às pesquisas dos temas selecionados, o professor deve ser o responsável pelo preparo das fontes iniciais, garantindo a qualidade dos materiais e fornecendo aos alunos as primeiras informações. Afinal, "quando os professores prestam maior grau de auxílio nessas determinações, há uma maior garantia de que a experiência de ABP abrangerá objetivos e padrões educacionais específicos" (BENDER, 2014, p. 39). Não se pode esquecer que, por ser uma proposta de ensino diferenciada, "em vez de servirem como fornecedores de informações (...), a ABP requer que os professores sejam facilitadores e orientadores educacionais, à medida que os estudantes avancem em suas atividades de projeto" (BENDER, 2014, p. 38).

É também componente essencial da ABP a criação de um produto final, no caso, o vídeo. Essa escolha se deu em um diálogo direto com a BNCC, que coloca como uma de suas competências gerais

compreender, utilizar e criar tecnologias digitais de informação e comunicação de forma crítica, significativa, reflexiva e ética nas diversas práticas sociais (incluindo as escolares) para se comunicar, acessar e disseminar informações, produzir conhecimentos, resolver problemas e exercer protagonismo e autoria na vida pessoal e coletiva. (BRASIL, 2018, p. 9)

Para realizar o projeto, os recursos do Google for Education foram essenciais. Gratuitos para as escolas mediante um cadastro, eles compõem um conjunto de ferramentas virtuais online: editores de textos e de slides, agenda, bloco de notas, entre outros. Nas atividades aqui descritas, fez-se muito uso das salas de aulas virtuais, pelas quais é possível interagir por um mural, pedir e entregar tarefas. Nelas, o professor pode dar o feedback e as notas aos alunos, concentrando as informações das atividades em um só local, acessível de qualquer lugar, a qualquer hora. Os alunos podem também trabalhar colaborativamente sem a necessidade de se 
encontrarem, facilitando a integração e permitindo ao professor a supervisão de todas as etapas realizadas.

A integração desses recursos com a criação de um vídeo alinha-se às demandas dos estudantes do século XXI, já tão familiarizados com as tecnologias. Por isso, a ABP configurase como uma interessante estratégia para trabalhar livros literários, distanciando-se das tarefas tradicionais, contando com "a formulação de uma questão motriz para o estudo, a voz e a escolha dos alunos inerentes à abordagem da $\mathrm{ABP}$, a natureza cooperativa das tarefas de $\mathrm{ABP}$, prazos maiores, profundidade do conteúdo abordado" (BENDER, 2014, p.31).

\section{0 planejamento e a execução do projeto}

A ideia do projeto aqui apresentado surgiu diante da necessidade de desenvolver atividades diferenciadas para o trabalho com o livro literário em sala de aula. Nos Anos Finais do Ensino Fundamental, os alunos parecem mais distantes da leitura e o trabalho com os livros torna-se desinteressante: o tradicional modelo de provas e questionários não corresponde mais às necessidades dessa geração.

Diante disso, a ABP se torna uma opção interessante por permitir que o aluno tenha protagonismo na escolha do tema de seu estudo, dando a ele autonomia e prazer na aprendizagem. Mais do que isso, ela permite trabalhos interdisciplinares, em que os professores orientam os alunos em seu processo de estudo e desenvolvimento.

O projeto foi desenvolvido com três turmas de $7^{\circ}$ ano do Ensino Fundamental, totalizando 81 alunos e envolvendo quatro disciplinas: Português, Redação, História e Geografia. O livro selecionado, utilizado como âncora, foi Diálogos de Samira: por dentro da guerra síria, de Marcia Camargos e Carla Caruso, publicado pela editora Moderna em 2015. Nele, conhece-se a história de Samira e Karim: ela, menina brasileira e descendente de libaneses; ele, menino sírio, que vive refugiado no Líbano. As mães das duas crianças haviam se conhecido por questões profissionais, sendo ambas professoras universitárias. Quando Samira tem curiosidades sobre sua origem e a cultura árabe, sua mãe sugere que comece a trocar e-mails com Karim para poder fazer perguntas e conhecer mais sobre aquela realidade cultural diretamente com quem a vive. Assim, inicia-se a correspondência dos dois, ambos com 12 anos. Karim conta à Samira seu dia a dia como refugiado e explica a ela os acontecimentos da Síria que o levaram a migrar para o Líbano, ao mesmo tempo em que a menina lhe conta seus hábitos 
de lazer e sua vida na escola. Aos poucos, Karim e Samira vão percebendo as semelhanças entre eles, os mesmos medos e desejos, mas separados geográfica e culturalmente.

A escolha deste livro se deu pela atualidade de seu tema, uma vez que, diariamente, os alunos se deparavam com notícias sobre a guerra na Síria. Porém, quantos estudantes do $7^{\circ}$ ano do Ensino Fundamental, com apenas 12 anos, como as personagens do livro, entendem o conflito? Na verdade, a questão é tão complexa que mesmo para os adultos é difícil explicá-la. No entanto, as autoras do livro conseguiram, por uma linguagem acessível e pelo diálogo entre duas crianças, colocar de forma amena tal tema. Marcia Camargos é jornalista com pósdoutorado em História pela USP, tendo viajado pelo Oriente Médio, acompanhando sua política e conhecendo sua cultura. Carla Caruso, formada em Letras pela PUC-SP, trabalha com oficinas de criação literária, além de ser escritora e ilustradora. Assim, a dupla de autoras desenvolveu uma obra extremamente adequada a estudantes dos Anos Finais do Ensino Fundamental, contando, inclusive, com um glossário ao final, explicando diversos termos destacados ao longo da narrativa.

Desenvolvido por quatro professoras, o projeto teve um tempo longo de realização, totalizando nove meses: iniciou-se em março e foi finalizado em novembro de 2018. Seu planejamento, porém, começou no final do ano letivo de 2017, quando a ideia surgiu. Pensado para ser uma oportunidade de os alunos reconhecerem sua humanidade a partir da percepção da humanidade do outro, o projeto envolveu aulas nas disciplinas de Português, Redação, História e Geografia, determinando, como produto final, a criação de um vídeo pelos próprios alunos.

A escolha do vídeo como produto vai ao encontro da BNCC, destacando que

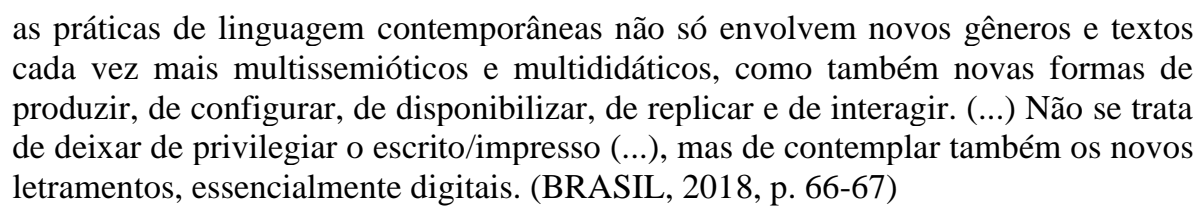

Nas aulas de Português, coube à professora acompanhar a leitura do livro, com debates sobre os temas que apareciam e as curiosidades geradas nos alunos. As orientações prévias do projeto, a divisão dos grupos, a escolha dos temas e as primeiras orientações de pesquisa também foram feitas nessa disciplina. Ela funcionou como o eixo em torno do qual as três outras se organizaram, sendo também ponto de apoio para os alunos.

Para compreender o(s) universo(s) de Samira e Karim, crianças protagonistas de diferentes realidades, assim como a construção da relação estabelecida entre eles, a professora de História lhes explicou a Guerra da Síria, seu principal contexto. Partiu-se da Primavera Árabe, iniciada em 2011, marca do início dos protestos populares no mundo árabe contra 
governos ditatoriais. Passou-se à sua particularização na Síria, à ainda presente guerra civil. Com a guerra materializada em fotos, vídeos, mapas, gráficos, dados estatísticos, depoimentos e diálogos entre as personagens, além do conhecimento prévio sobre o islamismo, os estudantes refletiram sobre os que sofrem com tal violência - dores, medos, mortes. Apontaram-se grupos e nações belicamente envolvidos e a avassaladora participação de seu governo autocrático. Tratou-se também da compreensão da condição de refugiado e da negação do mundo em seu acolhimento. Enfim, a História pôde proporcionar a compreensão do absurdo que a guerra é, pela sensibilização diante da vida de seus agentes, renegados pelo silêncio, pela indiferença e pelo abandono de seus pares.

Já na disciplina de Geografia, a professora optou por iniciar sua abordagem com slides contextualizando a divisão dos continentes, sendo este um tema já trabalhado com os alunos no $6^{\circ}$ ano. Em seguida, o foco se deslocou para o continente asiático, destacando a distância física que separava Samira e Karim. Mostrando as diferentes formas de se dividir o imenso continente asiático, o trabalho ajustou o recorte à posição geográfica da porção denominada Oriente Médio. Por imagens, destacou-se o Líbano, onde vivia Karim. Após tais exposições, os alunos foram convidados a enumerar os locais por onde o personagem passou ao longo da narrativa desde sua saída da Síria. Com imagens desses pontos, os estudantes foram se familiarizando com o espaço em que toda a história se desenrolava.

Como quarta disciplina envolvida, Redação foi responsável pelas orientações de produção do vídeo. Partindo de um trabalho prévio sobre o texto dramático, a professora retomou a estrutura e as características desse gênero textual para desenvolver nos alunos as habilidades necessárias para a criação do roteiro de seus vídeos, etapas a serem descritas posteriormente.

Durante todas as atividades, foi ferramenta essencial para o trabalho o Google Classroom, uma sala de aula virtual. Alimentada pelas professoras, ela podia ser acessada pelos alunos em qualquer lugar, por computador, tablet ou celular. Contando com um mural, semelhante ao de redes sociais, e dando a possibilidade de pedir e entregar tarefas virtualmente, ela facilitou e agilizou as atividades. Os alunos puderam trabalhar em documentos, em apresentações e no próprio vídeo a ser criado de maneira colaborativa, sem a necessidade de se encontrarem pessoalmente: cada um editava o trabalho na hora em que podia e, depois, os outros colegas complementavam, sempre vendo o que o outro já fizera. Os grupos formados pelos alunos foram escolhidos por eles mesmos, com quatro ou cinco componentes, a depender do número de estudantes em cada turma. Já tendo sido feitas, nas quatro disciplinas, as primeiras 
conversas sobre o livro, os grupos escolheram, a partir dos próprios interesses, temas de pesquisa motivados pela história - as questões motrizes. Nesse momento, a professora de Português atuou como mediadora, aconselhando para que os temas não ficassem genéricos ou específicos demais. Essa escolha se deu na própria sala de aula, de forma oral, inclusive com os alunos opinando sobre os temas de outros grupos que não os próprios. Foi um processo enriquecedor, uma vez que eles perceberam que escolher o que se vai pesquisar não é rápido ou simples, exige do pesquisador um olhar crítico e reflexivo sobre o assunto escolhido.

Ao final desse processo de escolha, os 18 grupos tinham escolhido 13 temas: alguns se repetiram em turmas diferentes. A enumeração desses temas mostra a diversidade dos interesses despertados nos alunos: Origem dos grupos Hezbollah, Hamas, Estado Islâmico e Al-Qaeda; As razões da guerra no Oriente Médio; Culinária e vestimentas árabes; Estado Islâmico; A acolhida dos refugiados no Brasil; O Islamismo; A Islamofobia; As grandes intolerâncias religiosas ao longo da História; Terrorismo: os grandes atentados; Síria: guerra e percepções; Refugiados: quem são, como vivem, preconceitos; Refugiados africanos; e A mulher muçulmana. As professoras, após isso, reuniram-se para determinar quais grupos seriam orientados por cada uma, sendo quatro ou cinco grupos por docente, acompanhando o que se propõe como ABP. Essa escolha se deu pela proximidade com o tema escolhido, ainda que as quatro professoras tenham ajudado com pesquisas sobre todos os temas. Vale ressaltar que, ao longo do projeto, foram feitos ajustes aos temas e às pesquisas diante das informações recolhidas pelos alunos e do encaminhamento que quiseram dar ao trabalho.

Depois de os alunos terem selecionado os temas e de terem sido feitas as primeiras abordagens em Português, História e Geografia, chegou o momento de eles pesquisarem sobre suas escolhas. Porém, é difícil, para alunos de 12 anos, analisar a qualidade das informações a que têm acesso pela internet. Por isso, na sala de aula do Google, as professoras disponibilizaram uma lista de fontes de pesquisa primária para cada um dos 13 temas, préselecionadas e avaliadas pelas quatro. Além disso, a cada nova fonte de pesquisa que os alunos encontrassem, deveriam procurar a professora orientadora do grupo para confirmar sua idoneidade e qualidade.

Tendo o projeto se iniciado em março, as etapas já descritas aconteceram até abril. Em maio, os alunos começaram a "colocar a mão na massa" em busca do vídeo final. Porém, pedir aos alunos um vídeo, ainda que orientando sobre o modelo, sem mostrar o que se espera, podia parecer impessoal, distante deles. Por isso, as professoras fizeram um vídeo primeiro. O objetivo desse vídeo foi substituir as instruções do trabalho: em vez de escrever o que se 
pretendia e como os alunos deveriam desenvolver as atividades, fez-se um vídeo, usando os recursos que se esperava serem utilizados pelos alunos, para demonstrar o resultado final esperado. Os alunos gostaram muito do modelo, pois viram que não era impossível e nem tão difícil assim fazer o que era proposto, afinal, as quatro professoras, consideradas por eles inábeis digitalmente, tinham conseguido.

A exibição desse filme coube à professora de Redação. Após o primeiro contato dos alunos com o vídeo, ela entregou um material contendo seu roteiro. Após uma leitura em conjunto, explicando os passos seguidos para a criação do vídeo, os estudantes perceberam que o produto final era somente uma parte do processo. Com o material em mãos, eles assistiram novamente ao vídeo e, dessa vez, tiveram o olhar direcionado para observarem roteiro e vídeo simultaneamente, a fim de perceber como ambos, texto e vídeo, eram lados diferentes da mesma moeda. Eles constataram que tudo que aparecia no vídeo estava marcado no roteiro, dos recursos utilizados às falas que acompanhavam as imagens. Puderam perceber, assim, o trabalho que as quatro professoras tiveram para fazer o vídeo instrucional e já anteciparam tudo o que precisariam fazer, passando à escritura de seus próprios roteiros.

Obviamente, houve mudanças entre o planejamento e o produto final, o que permitiu que os alunos percebessem o quanto planejar é importante e como as reformulações desse planejamento são naturais. Com esse material e com a pesquisa em mãos, os estudantes criaram, então, os roteiros de seus próprios vídeos. Após uma primeira leitura e correção, voltada para sugestões, eles fizeram uma segunda versão e puderam passar à elaboração concreta dos vídeos, com a $1^{\mathrm{a}}$ versão a ser entregue no mês de junho.

Ainda no mês de maio, os alunos passaram por duas outras experiências de enriquecimento no projeto. A primeira delas se trata de um estudo do meio, em que os alunos deixaram sua cidade de origem, São José dos Campos, no interior de São Paulo, e foram à capital paulista em uma saída pedagógica intitulada São Paulo de Todas as Crenças. Sob a orientação das professoras de História, Geografia e Português e de um guia especializado, os alunos conheceram quatro templos religiosos: a Catedral Metropolitana Ortodoxa, a Mesquita Brasil, a Congregação Israelita Paulista e o Tempo Budista Tzong Kwan. Conversando com o guia e com religiosos dos quatro templos, os alunos conheceram diversas fés, fizeram perguntas, vivenciaram ritos religiosos diversos e enriqueceram seus olhares sobre a realidade dos outros, ponto chave de todo o projeto. Complementando essa proposta, os alunos receberam na escola, para uma conversa, um refugiado sírio que vive em São Paulo desde 2013. Foi uma experiência riquíssima, pois eles relacionaram a conversa ao livro lido, conhecendo alguém que viveu muito 
do que foi descrito ficcionalmente. Além de ouvirem o relato do palestrante, puderam fazer perguntas e trocar ideias, construindo ativamente uma nova visão sobre o tema.

Após essas etapas, no início do mês de junho os alunos entregaram, via Google Classroom, a primeira versão do vídeo. As quatro professoras reuniram-se para assisti-los, mas sem dar notas ou fechar avaliações. Na verdade, fizeram-se anotações sobre o que estava bom e o que podia ser melhorado em cada vídeo. Em seguida, cada professora orientadora se reuniu com seus grupos e os orientou sobre mudanças possíveis no vídeo, explicando as inadequações, fossem elas no formato ou no conteúdo, e elogiando os pontos positivos. Marcou-se, então, a entrega da segunda versão apenas para o final do mês de agosto, visto que julho era inteiro de férias.

Após a entrega da segunda versão, houve nova reunião das quatro professoras para a avaliação final dos vídeos. Dos 18 grupos, 13 foram considerados excelentes, adequados quanto ao formato e ao conteúdo; quanto aos 5 restantes, foi dada a eles a possibilidade de fazerem mais ajustes e entregar uma terceira versão do vídeo duas semanas depois da avaliação final.

Como finalização do trabalho, foi feita uma mostra dos vídeos para os próprios alunos, em que as três turmas assistiram aos trabalhos de todos, opinando e comentando tanto sobre o formato dos vídeos quanto sobre os temas abordados. Por uma questão de ajustes de calendário, não pôde ser feita uma mostra em que os pais estivessem presentes, o que havia sido idealizado pelos próprios alunos ao longo do processo. Porém, o entusiasmo dos alunos ao verem seus vídeos e ouvirem os comentários dos colegas contagiou a todos, mostrando que, quando se sentem protagonistas do aprendizado, os estudantes dão a ele significado e se envolvem no processo do início ao fim.

\section{Resultados}

O projeto aqui descrito ambicionou que os alunos se apropriassem da leitura, percebendo a obra literária como muito mais do que um complemento às aulas de Português. Pretendeu-se o reconhecimento da literatura como instrumento para a percepção do mundo e do outro, em um processo de humanização. Mais do que avaliar a leitura, aferindo fatos da narrativa, o objetivo foi desenvolver o gosto pela leitura ao percebê-la como forma de ler e entender o mundo. Afinal, "é preciso estar aberto à multiplicidade do mundo e à capacidade da palavra de dizê-lo para que a atividade de leitura seja significativa" (COSSON, 2016, p. 27).

Como resultado prático do projeto, os alunos criaram vídeos com os mais variados temas, apresentando uma visão crítica sobre assuntos difíceis, que, a princípio, não pareceriam 
de interesse de jovens de 12 anos. As pesquisas feitas como base foram profundas, com mais de uma fonte, sempre relacionadas ao livro. A partir de uma leitura significativa, os estudantes deram valor às pesquisas feitas e, assim, puderam confrontar questões e problemas do mundo real, dando a eles significado e importância. Cada aluno pôde, como colocado por Colomer (2007, p. 61), vivenciar a "ampliação das fronteiras do mundo conhecido", tendo o livro o poder de fazê-lo "penetrar em outros modos de vida, mostrar-lhe realidades desconhecidas e proporcionar-lhe o eterno prazer de quem se senta ao lado do viajante que regressa".

Ao escolherem o tema pesquisado e o formato do vídeo, puderam desenvolver a autonomia e o protagonismo, em um processo reflexivo de produção de conhecimento. Reconheceram, assim, que seus interesses têm espaço na escola, não precisam se desenvolver apenas fora dela. Além disso, apropriaram-se de tecnologias, incorporando-as como reais instrumentos de ensino e aprendizagem, usando recursos familiares a eles para a criação do produto final. Puderam perceber que instrumentos vistos, a princípio, como apenas para o lazer podem ser ricas ferramentas de trabalhos escolares.

Quanto à avaliação do projeto, ela foi gradativa, processual, com todas as etapas reconhecidas como essenciais ao produto final. Embora tenha-se gerado uma nota para as atividades, elas não foram o foco. $\mathrm{Na}$ verdade, a qualidade dos trabalhos foi tão alta que a maioria dos grupos teve notas bastante altas ao longo de todo o processo, corroborando a ideia de que envolver ativamente os alunos no processo é essencial para uma aprendizagem significativa.

\section{Considerações finais}

Ler é um ato crítico, reflexivo, de conhecimento do mundo e de si mesmo. Já Antonio Candido (1995) deixou claro que a Literatura se relaciona com todas as outras esferas da existência humana e, por isso, o direito a ela é inegável e essencial a todo ser humano. Cabe à escola estimular e desenvolver o gosto pela leitura literária nos alunos, mostrando a eles que se apropriar da palavra é também se apropriar de si e do mundo. Como colocado por Colomer (2007, p. 68), “é útil pensar a educação literária como uma aprendizagem de percursos e itinerários de tipo e valor muito variáveis. A tarefa da escola é mostrar as portas de acesso. A decisão de atravessá-las e em que medida depende de cada indivíduo".

Nas salas de aula, o livro precisa ser visto como um meio, e não como um fim, pois "não é possível aceitar que a simples atividade da leitura seja considerada a atividade escolar de 
leitura literária" (COSSON, 2016, p. 26). Leituras para fazer provas não reconhecem o ato de ler como significativo, é preciso ir além das perguntas e respostas. Os alunos precisam ser incentivados a pensar, a se posicionarem, a terem opiniões sobre o que leem, reconhecendo que não há literatura "boa" ou "má", e sim literaturas, adequando-se aos gostos e às percepções de cada um. Eles necessitam também perceber na literatura

a possibilidade de multiplicar ou expandir a experiência do leitor através da vivência dos personagens e a oportunidade de explorar a conduta humana de modo compreensível. (...) É através dessa experiência tão particular de sonhar-se a si mesmo que se dá ao leitor um instrumento poderoso de construção pessoal e uma completa dimensão educativa sobre os sentimentos e ações humanas (COLOMER, 2007, p. 61).

Diante disso, o projeto descrito neste relato mostrou-se bem-sucedido em promover um ambiente multidisciplinar centrado no aluno, usando as tecnologias como facilitadoras da comunicação e como ferramentas de produção de saberes. A escolha da ABP provou-se acertada, pois, a partir de um livro pré-selecionado, deu aos alunos o poder de escolher o que pesquisar, fazendo-os se sentirem integrados a todo o processo.

Os alunos se interessaram por temas considerados, a princípio, distantes deles, e, ao pesquisarem, reconheceram semelhanças e perceberam diferenças, conscientizando-se sobre a pluralidade do mundo. Se antes as atividades de leitura pareciam a eles enfadonhas, tornaramse interessantes e diferentes. Foi surpreendente perceber a qualidade dos vídeos criados, muitas vezes por alunos que, em sala, pareciam desinteressados e pouco estimulados. As professoras reconheceram, em todas as turmas envolvidas, excelentes editores de vídeo, bons narradores, alunos criativos, estudantes com perfis de liderança, outros muito prestativos, até com grupos que não os próprios, entre várias outras percepções. Houve casos de alunos que buscaram outros livros, filmes e séries relacionadas aos temas pesquisados e muitos até relataram conversas com pais e familiares sobre o que estudavam em sala. Em alguns casos, a identificação pessoal com o tema pesquisado chamou a atenção: três estudantes tinham ascendência libanesa e envolveram os familiares nas pesquisas e até na filmagem dos vídeos.

Quanto à escola, o projeto foi considerado tão bem realizado que, para o ano letivo seguinte, 2019, pediu-se a expansão do modelo para outras séries e outras disciplinas, com temas variados. A ABP tornou-se uma metodologia a ser incorporada por todo o corpo docente, usando-se a experiência aqui descrita como ponto norteador.

Retomando as ideias de Coelho (2000), o projeto permitiu que a literatura não fosse percebida apenas como parte de uma "disciplina escolar", mas que se tornasse reconhecida por seu potencial como eixo estruturador, promovendo a interpenetração das disciplinas a partir da leitura e de seu proveito. Com os recursos do Google for Education, foi possível, como 
preconizado pela BNCC, "mobilizar práticas da cultura digital, diferentes linguagens, mídias e ferramentas digitais para expandir as formas de produzir sentidos (nos processos de compreensão e produção), aprender e refletir sobre o mundo e realizar diferentes projetos autorais" (BRASIL, 2018, p. 85), atendendo a demandas dos próprios alunos por aulas mais interessantes e atividades mais dinâmicas.

Vê-se, enfim, que há possibilidades de trabalho com literatura em sala de aula que desenvolvem o gosto pela leitura. Pode ser complexo, exigir do professor a reformulação de suas práticas, demandar tempo e recursos diferenciados, mas é, sem dúvida, possível. Melhor: é bem-sucedido.

\section{Referências}

BENDER, William. Aprendizagem baseada em projetos: educação diferenciada para o século XXI. 1. ed. Porto Alegre: Penso, 2014.

BRASIL. Ministério da Educação. Base Nacional Comum Curricular. Disponível em: http://basenacionalcomum.mec.gov.br/wp-content/uploads/2018/02/bncc-20dez-site.pdf. Acesso em 11/10/2018.

CAMARGOS, Marcia. CARUSO, Carla. Diálogos de Samira: por dentro da guerra síria. 1. ed. São Paulo: Moderna, 2015.

CANDIDO, Antonio. O direito à literatura. In: Vários escritos. São Paulo: Duas Cidades, 1995. p. 235-263.

COELHO, Nelly N. A Literatura: um "fio de Ariadne" no labirinto do ensino neste limiar de milênio? In: Literatura: arte, conhecimento e vida. Ed. Fundação Peirópolis. 2000. p. 13-31.

COLOMER, Teresa. Andar entre livros: a leitura literária na escola. Tradução de Laura Sandroni. São Paulo: Global, 2007.

COSSON, Rildo. Letramento literário: teoria e prática. 2. ed. São Paulo: Contexto, 2016.

COSTA, Maria C. C. A leitura das imagens. In: ZILBERMAN, Regina; ROSING, Tania. M. K. Escola e leitura: velha crise, novas alternativas. São Paulo: Global, 2009. p.81-98.

MARTINS, Ivanda. A literatura no ensino médio: quais os desafios do professor? In: BUNZEN, Clécio; MENDONÇA. Márcia. (org.). Português no Ensino Médio e formação do professor. São Paulo: Parábola Editorial, 2006. p. 83-102. 
ROJO, Roxane. Letramento(s): práticas de letramento em diferentes contextos. In: Letramentos múltiplos, escola e inclusão social. $1^{\text {a }}$ edição. São Paulo: Parábola editorial, 2009. p.95-121.

ROJO, Roxane. Letramento e capacidades de leitura para a cidadania. Disponível em: http://arquivos.info.ufrn.br/arquivos/2013121153a8f1155045828c12733b68e/Letramento_e_c apacidade_de_leitura_pra_cidadania_2004.pdf. Acesso em 10/09/2018.

ROUXEL, Annie. Aspectos metodológicos do ensino da literatura. In: DAVI, Maria A.; REZENDE, Neide L.; JOVER-FALEIROS, Rita. (org.) Leitura de literatura na escola. São Paulo, SP: Parábola, 2013. p. 17-33. 